\title{
DIALOGUE:
}

\section{IS NEW CLASSICAL ECONOMICS A FALSE PATH OR AN ILLUMINATING COMPLEMENT TO KEYNESIAN ECONOMICS?}

This is the second installment of our new occasional feature: Dialogue. The purpose of this feature is to highlight and encourage debate and discussion on economic issues. Candidates for inclusion in this feature are submissions that extend, significantly modify, or contradict the findings of an article previously published in the Eastern Economic Journal. Any such submission undergoes the normal review process, with the exception that one of the referees is the author of the EEJ article addressed by the new paper. If the paper is ultimately accepted for publication, that referee is invited to write a short comment on the final draft which will then be published along with it. We encourage our readers to submit papers that build on work previously published in this Journal and would thus be candidates for future rounds of Dialogue.

In "The New Classical Counter-Revolution: False Path or Illuminating Complement?" Brian Snowdon responds to Laurence S. Seidman's 2005 EEJ Forum piece, "The New Classical Counter-Revolution: A False Path for Macroeconomics" (31: 13140). Snowdon identifies five lines of argument in Seidman's piece and proceeds to a well-reasoned critique of these points. Seidman then replies to this article, articulating why he remains "convinced that the new classical economics has been a false path for macroeconomics." This is an important topic on which we are glad to see continued discussion.

Joyce P. Jacobsen

Gilbert L. Skillman

Eastern Economic Journal, Vol. 34, No. 4, Fall 2007 